\title{
Testing the Psychometric Properties of the Modeling Self-Efficacy Scale
}

\author{
Anu Sharma \\ Chamberlain College of Nursing \\ Stephen J. Pape \\ Johns Hopkins University \\ Jonathan Templin \\ University of lowa
}

\begin{abstract}
The Modeling Self-Efficacy Scale was developed to measure students' confidence in understanding and solving modeling tasks. The scale was administered to 225 eighth- and ninth-grade students. Participants read modeling tasks adapted from Programme for International Student Assessment's 2003 problem-solving assessment and rated their confidence on a 100-point self-efficacy scale. Confirmatory factor analysis indicated that modeling self-efficacy is a unidimensional construct, best elicited by a repeated-measuresstyle survey design in which participants responded to the same self-efficacy items across multiple modeling problems. The omega reliability coefficient for the scale was .88 . The findings suggest that the Modeling Self-Efficacy Scale is a reliable and valid instrument for middle and high school mathematics students.
\end{abstract}

Keywords: mathematical modeling, self-efficacy, reliability, validity

\section{Introduction}

Today's global society, changing economy, and rapid technological advances require students to become creative thinkers and effective problem solvers (English, Lesh, \& Fennewald, 2008). Although technology reduces the complexity involved in mathematizing real-world data, it places increased demands on students to interpret the data and communicate the results. Modern conceptions of mathematics education emphasize engaging students in modeling activities that foster these 21st-century skills and abilities (English \& Sriraman, 2010; Galbraith, Stillman, \& Brown, 2010). Modeling with mathematics is the process of using knowledge and skills from across and within a curriculum to represent, analyze, make assumptions, and resolve problems arising in everyday life (Guidelines for Assessment and Instruction in Mathematical Modeling Education, 2016; National Governors Association Center for Best Practices \& Council of Chief State School Officers, 2010). Modeling problems embedded in real-world situations are cognitively demanding and require translation across real-world knowledge related to the task context and mathematical concepts and skills (Blum \& Ferri, 2009; Lesh, Yoon, \& Zawojewski, 2007). Results from the Programme for International Student Assessment studies in 2003 and 2006 provide evidence that modeling problems are challenging for students from all over the world (Organisation for Economic Co-Operation and Development [OECD], 2004, 2007). We developed the Modeling Self-Efficacy Scale (MSES) in response to the importance of the self-efficacy construct in influencing students' mathematical problem-solving achievement related to the process of modeling. The present study examines and reports the psychometric properties of the MSES. To this end, a brief overview of the

Please address queries to: Anu Sharma, Chamberlain College of Nursing, 1221 North Swift Road, Addison, IL 60101. Email: shivankanu@gmail.com 
self-efficacy construct in academic settings and modeling problems is provided, followed by the description and key findings. The article concludes with the discussion of results and suggestions for future research in this area.

Self-efficacy beliefs refer to individuals' judgments about their capability to accomplish a particular task (Bandura, 2006). In academic settings, particularly mathematics, self-efficacy refers to students' judgments of their abilities to solve mathematics problems, perform mathematics-related tasks, or engage in mathematics activities (Pajares, 1996). These beliefs reflect students' judgments about how well they will perform a task in the future rather than their current performance level. Selfefficacy beliefs are related to and predictive of students' problem-solving achievement, and are measured by asking students to report their confidence in their ability to solve mathematical problem-solving tasks (Nicolaidou \& Philippou, 2002; Pajares \& Graham, 1999; Pajares \& Kranzler, 1995). Efficacy judgments positively influence students' engagement with complex tasks, persistence in accomplishing complex tasks, and amount of cognitive effort exerted during problem-solving activities (Schunk \& Mullen, 2012). Students' confidence in their abilities predicts success in mathematics better than anxiety about mathematics (Pajares \& Miller, 1994), prior math experience (Pajares \& Miller, 1994), and attitudes toward mathematics (Nicolaidou \& Philippou, 2002).

Moreover, Pajares and Kranzler (1995) found stronger direct effects of students' self-efficacy beliefs on mathematical problem-solving performance when general mental ability was controlled. The significant relationship between self-efficacy beliefs and mathematics achievement suggests that students' perceptions of their own ability to understand and analyze modeling tasks may influence their success in solving these tasks.

Modeling problems embedded in real-world contexts require students to understand, interpret, and mathematize realistic situations by selecting or acquiring appropriate mathematical concepts, procedures, and problem-solving strategies (Blum \& Ferri, 2009; Lesh et al., 2007; Zawojewski, 2010). Students who are engaged in the iterative cycles of modeling tasks progressively create, test, revise, and refine their own mathematical assumptions and interpretations (Lesh \& Doerr, 2003; Guidelines for Assessment and Instruction in Mathematical Modeling Education, 2016). As such, mathematical modeling is the process during which students develop deeper understanding of mathematics by exploring, analyzing, and interpreting real-world problems. Considering the fact that modeling problems are more cognitively demanding than usual mathematics textbook problems, it is inappropriate to use the typical method of confidence reporting to measure students' self-efficacy beliefs for modeling tasks. Bandura (2006), in his guide to constructing self-efficacy scales, argued that these scales should measure confidence in behaviors that are relevant to the domain of functioning and behaviors that individuals can control. Thus, to understand students' self-efficacy beliefs associated with modeling tasks, we developed a self-efficacy scale that measures students' confidence on a range of subskills associated with understanding and solving modeling tasks. To construct the MSES, we drew upon self-efficacy theory (Bandura, 2006; Pajares, 1996; Schunk \& Pajares, 2009) and research highlighting the knowledge and skills necessary to solve modeling tasks (Blum \& Ferri, 2009; Lesh \& Doerr, 2003; English \& Sriraman, 2010). The purpose of the present study was to examine the MSES's psychometric properties with middle and high school students.

\section{Method}

\section{Participants}

A total of 225 Grade $8(n=88,39.11 \%)$ and Grade $9(n=137,60.8 \%)$ students from 13 classrooms participated in the study. The average age of the participants was $14.22(S D=0.85)$. The number of female participants $(n=122,54.2 \%)$ was slightly higher than the number of male participants $(n=$ 
103, 45.8\%). Participants reported their ethnicity as White $(n=111,49.3 \%)$, African American $(n=$ 46, 20.44\%), Hispanic ( $n=33,14.6 \%)$, Asian $(n=12,5.33 \%)$, and Native Hawaiian $(n=1,0.44 \%)$. The remaining participants reported their ethnic background as either a combination of the ethnicities listed ( $n=19,8.4 \%)$ or as "other" ( $n=3,1.33 \%)$.

\section{Materials}

We developed the MSES by drawing upon research highlighting the knowledge and skills necessary to solve modeling tasks (Blum \& Ferri, 2009; English \& Sriraman, 2010; Lesh \& Doerr, 2003) and by following Bandura's (2006) recommendations for developing self-efficacy scales. The modeling problems that formed the basis for the MSES were adapted from the Programme for International Student Assessment's 2003 problem-solving assessment (OECD, 2004) because they are regarded as complex modeling tasks (Blum \& Ferri, 2009; Carreira, Amado, \& Lecoq, 2011; Mousoulides, 2007; Mousoulides, Christou, \& Sriraman, 2008). Participants' modeling performance was tested on three different types of tasks: decision-making, system analysis and design, and troubleshooting (OECD, 2004; see Appendix A for an example of each type of task). The decision-making tasks measured the extent to which participants could make appropriate decisions by strategically choosing among several alternatives provided under a given set of conditions. The system analysis and design tasks required participants to identify complex relationships among the variables or to design a system (e.g., a table) by satisfying all the conditions given in a problem. The third type of task, troubleshooting problems, required participants to diagnose, rectify, and improve a faulty or underperforming system.

Subsequently, we designed the MSES to measure students' confidence in understanding, mathematizing, and solving these modeling problems using the guidelines for processes essential to solving the tasks prescribed. For each problem presented, study participants responded to four selfefficacy questions: (a) How sure are you that you can understand this mathematical problem? (b) How sure are you that you can determine a strategy to solve this problem? (c) How sure are you that you can determine the information required to solve this problem? (d) How sure are you that you can solve this mathematical problem correctly?

Participants recorded the strength of their efficacy beliefs on a 100-point scale, divided into 10-unit intervals ranging from 0 (not at all sure) to 100 (very sure; see Appendix B) after reading each problem. Experts in psychological construct and measurement reviewed MSES items, establishing a degree of content validity for the MSES.

\section{Procedure}

Participants were first provided an explanation of the importance of reporting accurate and honest efficacy judgments. Next, they reported their confidence in solving six modeling tasks. Participants completed this task in approximately $20 \mathrm{~min}$. After recording their confidence on the MSES, participants solved these problems in approximately $45 \mathrm{~min}$. For the purposes of the present study, we report only data related to students' self-efficacy ratings for the six modeling problems.

\section{Data Analysis}

We evaluated the dimensionality of the MSES scale using confirmatory factor analysis (CFA) by examining the overall model fit and factor loadings of the hypothesized measurement model in Mplus Version 7.11 (Muthén, Muthén, Asparouhov, \& Nguyen, 2013). The measurement model represents relationships between observed indicators (i.e., students' self-efficacy scores) and the underlying latent factors (i.e., the overall self-efficacy construct) they are supposed to measure. 
Additionally, as the MSES featured four self-efficacy questions per modeling problem, method factors for each problem were incorporated into the analysis to control for any additional dependencies with problems. We tested the overall model fit by examining goodness-of-fit indices such as chi-square test of model fit, the root mean square error of approximation, the comparative fit index, and the TuckerLewis index. Readers are encouraged to refer to Byrne (2012) for a more detailed description of methods for examining model fit in CFA. Once verifying good model fit to establish the dimensionality of the MSES, the reliability of the scale was estimated using McDonald's (1999) omega coefficient.

\section{Findings}

As the four self-efficacy items were measured repeatedly over six items, each self-efficacy item was provided its own specific factor. An overall self-efficacy higher order factor was defined to be measured by the four self-efficacy factors. Each of the six problems was hypothesized to affect the general self-efficacy report of a participant, and therefore, each was modeled with its own methods factor. Finally, as the modeling problems fell under a common domain, we defined a higher order overall modeling construct by loading all the methods or problem factors on it, leaving it uncorrelated with the higher order self-efficacy factor.

The goodness of fit indicated the model fits the data well, $\chi^{2}(218, n=225)=273.37, p=.006$, comparative fit index $=.99$, Tucker-Lewis index $=0.99$, root mean square error of approximation $=.03,90 \%$ confidence interval $[.02, .04]$. All the observed variables had significant factor loading on the overall MSES with factor loadings ranging from .66 to .86 (see Table 1). All estimates were statistically significant, and all standard errors values were in good order. Having established good model fit, we then estimated the omega reliability of the higher order self-efficacy factor to be .88, suggesting very high reliability for the measurement of self-efficacy by the MSES. Because the analysis yielded good model fit and high reliability, it suggests that self-efficacy is a unidimensional construct as hypothesized. We note that, although the analysis model itself featured multiple factors, each was necessary because of the design of the MSES with repeated self-efficacy questions across multiple problems. With all design effects modeled, the higher order factor for self-efficacy is the unidimensional construct of self-efficacy we hypothesized.

Table 1. Confirmatory Factor Analysis for the Measurement Model

\begin{tabular}{lcc}
\hline Parameter & Standardized Factor Loading & Error Variance \\
\hline $\begin{array}{l}\text { Confidence in understanding a } \\
\text { problem }\end{array}$ & $.86(.06)$ & $.26(.10)$ \\
Confidence in determining a strategy & & $.32(.16)$ \\
Confidence in determining the & $.83(.10)$ & $.22(.12)$ \\
$\quad$ information & $.88(.07)$ & $.57(.20)$ \\
\hline
\end{tabular}

Note. Standard errors are in parentheses. All variables were statistically significant at $p=.00$.

\section{Discussion}

The purpose of this study was to investigate the psychometric properties of a new self-efficacy measure, the MSES. Omega model-based reliability indicates that the overall proportion of variance in students' self-efficacy scores due to the self-efficacy items on the MSES was .88. The dimensionality of the MSES, established using CFA, illustrates that the model fits well with the data, suggesting self-efficacy is a unidimensional construct best elicited by a repeated-measures- 
style survey design in which participants respond to the same self-efficacy items across multiple problem types. Because the dimensionality of the MSES was examined by defining the method factors and controlling for the influence of modeling problems, the scale can easily be used in future research studies to measure students' self-efficacy beliefs for any set of modeling problems. In conclusion, the present study has shown that MSES is a reliable and valid instrument for middle and high school students.

The development of the scale has contributed significantly to the self-efficacy and mathematical modeling literature and has important implications for future research. In the field of educational psychology, self-efficacy beliefs have been found to strongly influence individuals' motivation, persistence, expended effort, achievement, and self-regulation (Schunk \& Mullen, 2012; Schunk \& Pajares, 2009). Considering the fact that modeling problems situated in real-world contexts are cognitively demanding tasks compared to the word problems usually found in school mathematics, it is imperative that future research should investigate the relationship between self-efficacy beliefs and mathematical modeling achievement.

\section{References}

Bandura, A. (2006). Guide for constructing self-efficacy scales. In F. Pajares \& T. Urdan (Eds.), Selfefficacy beliefs of adolescents (pp. 307-337). Greenwich, CT: Information Age.

Blum, W., \& Ferri, R. B. (2009). Mathematical modeling: Can it be taught and learnt? Journal of Mathematical Modeling and Application, 1, 45-58.

Byrne, B. M. (2012). Structural equation modeling with Mplus: Basic concepts, applications, and programming. New York, NY: Routledge.

Carreira, S., Amado, N., \& Lecoq, F. (2011). Mathematical modelling of daily life in adult education: Focusing on the notion of knowledge. In G. Kaiser, W. Blum, R. B. Ferri, \& G. Stillman (Eds.), Trends in teaching and learning of mathematical modeling (pp. 199-210). New York, NY: Springer.

English, L. D., Lesh, R., \& Fennewald, T. (2008, July). Future directions and perspectives for problem solving research and curriculum development. Paper presented at the 11th international conference on mathematical education, Monterrey, Mexico.

English, L. D., \& Sriraman, B. (2010). Problem solving for the 21st century. In B. Sriraman \& L. English (Eds.), Theories of mathematics education: Seeking new frontiers (pp. 263-290). New York, NY: Springer.

Galbraith, P., Stillman, G., \& Brown, J. (2010). Turning ideas into modeling problems. In R. Lesh, P. L. Galbraith, C. R. Haines, \& A. Hurford (Eds.), Modeling students' mathematical modeling competencies (pp. 133-144). New York, NY: Springer.

Guidelines for Assessment and Instruction in Mathematical Modeling Education. (2016). Consortium of mathematics and its applications (COMAP). Philadelphia, PA: Society for Industrial and Applied Mathematics. Retrieved from: http://www.siam.org/reports/gaimme.php

Lesh, R., \& Doerr, H. M. (2003). Beyond constructivism: Models and modeling perspectives on mathematics problem solving, learning, and teaching. Mahwah, NJ: Lawrence Erlbaum.

Lesh, R., Yoon, C., \& Zawojewski, J. (2007). John Dewey revisited: Making mathematics practical versus making practice mathematical. In R. Lesh, E. Hamilton, \& J. Kaput (Eds.), Models and modeling as foundations for the future in mathematics education (pp. 313-349). Mahwah, NJ: Lawrence Erlbaum. 
McDonald, R. P. (1999). Test theory: A unified treatment. Mahwah, NJ: Lawrence Erlbaum.

Mousoulides, N. (2007). A modeling perspective in the teaching and learning of mathematical problem solving (Unpublished doctoral dissertation). University of Cyprus, Nicosia, Cyprus.

Mousoulides, N., Christou, C., \& Sriraman, B. (2008). A modeling perspective on the teaching and learning of mathematical problem solving. Mathematical Thinking and Learning, 10, 293-304.

Muthén, L., Muthén, B., Asparouhov, T., \& Nguyen, T. (2013). Mplus (Version 7.11) [Computer software]. Retrieved from http://www.statmodel.com/index.shtml

National Governors Association Center for Best Practices \& Council of Chief State School Officers (2010). Common Core state standards (mathematics). Washington, DC: National Governors Association Center for Best Practices. Retrieved from http://www.corestandards.org/wpcontent/uploads/Math_Standards.pdf

Nicolaidou, M., \& Philippou, G. (2002). Attitudes towards mathematics, self-efficacy and achievement in problem solving. In J. Evans, M. Hannula, G. Philippou, \& R. Zan (Chairs), Thematic working group 2: Affect and mathematical thinking: Symposium conducted at the third conference of the European Society for Research in Mathematics Education. Bellaria, Italy: European Society for Research in Mathematics Education. Retrieved from http://www.mathematik.unidortmund.de/ erme/CERME3/Groups/TG2/TG2_nicolaidou_cerm e3.pdf

Organisation for Economic Co-Operation and Development (OECD). (2007). Science competencies for tomorrow's world from PISA 2006. Retrieved from http://www.oecd.org/pisa/pisaproducts/pisa2006/39725224.pdf

Pajares, F. (1996). Self-efficacy beliefs in academic settings. Review of Educational Research, 66, $543-578$.

Pajares, F., \& Graham, L. (1999). Self-efficacy, motivation constructs, and mathematics performance of entering middle-school students. Contemporary Educational Psychology, 24, 124-139.

Pajares, F., \& Kranzler, J. (1995). Self-efficacy beliefs and general mental ability in mathematical problem solving. Contemporary Educational Psychology, 20, 426-443.

Pajares, F., \& Miller, D. (1994). Role of self-efficacy and self-concept beliefs in mathematical problem solving: A path analysis. Journal of Educational Psychology, 86, 193-203.

Schunk, D. H., \& Mullen, C. A. (2012). Self-efficacy as an engaged learner. In S. L. Christenson, A. L. Reschly, \& C. Wylie (Eds.), Handbook of research on student engagement (pp. 219-236). New York, NY: Springer.

Schunk, D. H., \& Pajares, F. (2009). Self-efficacy theory. In K. R. Wentzel \& A. Wigfield (Eds.), Handbook of motivation at school (pp. 35-53). New York, NY: Routledge.

Zawojewski, J. (2010). Problem solving versus modeling. In R. Lesh, P. L. Galbraith, C. R. Haines, \& A. Hurford (Eds.), Modeling students' mathematical modeling competencies (pp. 237-244). New York, NY: Springer.

[Appendices follow] 


\section{Appendix A}

\section{The Modeling Test}

\section{Decision-Making Task: Cinema Outing}

James, 15 years old, wants to organize a cinema outing with two of his friends, who are of the same age, during the 1-week spring break. The break begins on Saturday, March 24, and ends on Sunday, April 1. James asks his friends for suitable dates and times for the outing. He received the following information.

Mike: "I have to stay home on Monday and Wednesday afternoons for music practice between 2:30 and 3:30."

Richard: "I have to visit my grandmother on Sundays, so it can't be Sundays. I have seen Tower Heist and don't want to see it again."

James' parents insist that he only goes to movies suitable for his age and does not walk home. They will fetch the boys home at any time up to 10 p.m. James checks the movie times for the spring break. He finds the following information.

\begin{tabular}{|c|c|}
\hline \multicolumn{2}{|c|}{$\begin{array}{c}\text { Regal Cinema } \\
\text { 3702 West University Avenue } \\
\text { Gainesville, FL 32607 } \\
\text { Advance Booking Number: (352) 373-4277 } \\
\text { Bargain Day Tuesdays: All films } \$ 3\end{array}$} \\
\hline $\begin{array}{c}\text { Children in the Net } \\
1 \mathrm{hr} 53 \mathrm{~min} \\
2: 00 \text { p.m. (Mon-Fri only) } \\
\text { 9:35 p.m. (Sat-Sun only) } \\
\text { Suitable only for persons of } 12 \text { years and over }\end{array}$ & \begin{tabular}{|c|} 
Pokamin \\
1 hr 45 min \\
1:40 p.m. (Daily) \\
4:35 p.m. (Daily) \\
Parental Guidance \\
General viewing, but some scenes may be \\
unsuitable for young children
\end{tabular} \\
\hline $\begin{array}{c}\text { Monsters From the Deep } \\
2 \mathrm{hr} 44 \mathrm{~min} \\
7: 55 \text { p.m. (Fri-Sat only) } \\
\text { Suitable only for persons of } 18 \text { years and over }\end{array}$ & \begin{tabular}{|c|} 
Enigma \\
2 hr 24 min \\
3:00 p.m. (Mon-Fri only) \\
6:00 p.m. (Sat-Sun only) \\
Suitable for persons of 12 years and over
\end{tabular} \\
\hline $\begin{array}{c}\text { Carnivore } \\
2 \mathrm{hr} 28 \mathrm{~min} \\
6: 30 \mathrm{p} . \mathrm{m} . \text { (Daily) } \\
\text { Suitable only for persons of } 18 \text { years and over }\end{array}$ & \begin{tabular}{|c|} 
King of the Wild \\
1 hr 3 min \\
6:30 p.m. (Mon-Fri only) \\
6:50 p.m. (Sat-Sun only) \\
Suitable for persons of all ages \\
\end{tabular} \\
\hline
\end{tabular}




\section{Question 1: Cinema Outing}

Taking into account the information James found on the movies and the information he got from his friends, which of the six movies should James and the boys consider watching?

Circle "Yes/No" for each movie. Justify your responses.

\begin{tabular}{|l|c|}
\hline Movie & $\begin{array}{c}\text { Should the Three Boys Consider } \\
\text { Watching the Movie? }\end{array}$ \\
\hline Children in the Net & Yes/No \\
\hline Monsters From the Deep & Yes/No \\
\hline Carnivore & Yes/No \\
\hline Pokamin & Yes/No \\
\hline Enigma & Yes/No \\
\hline King of the Wild & Yes/No \\
\hline
\end{tabular}

\section{System Analysis and Design Task: Children's Camp}

The Florida Gator Community Service is organizing a 5-day children's camp. Forty-six children ( 26 girls and 20 boys) have signed up for the camp, and eight adults (four men and four women) have volunteered to attend and organize the camp.

\begin{tabular}{|l|}
\hline Teacher \\
\hline Mrs. Madison \\
\hline Mrs. Carroll \\
\hline Ms. Grace \\
\hline Ms. Kelly \\
\hline Mr. Stevens \\
\hline Mr. Neill \\
\hline Mr. Williams \\
\hline Mr. Peters \\
\hline
\end{tabular}

\begin{tabular}{|l|c|}
\hline Dormitory & $\begin{array}{c}\text { Number of } \\
\text { Beds }\end{array}$ \\
\hline Red & 12 \\
\hline Blue & 8 \\
\hline Green & 8 \\
\hline Purple & 8 \\
\hline Orange & 8 \\
\hline Yellow & 6 \\
\hline White & 6 \\
\hline
\end{tabular}

\section{Dormitory Rules:}

1. Boys and girls must sleep in separate dormitories.

2. At least one adult must sleep in each dormitory.

3. The adult(s) in a dormitory must be of the same gender as the children.

\section{Question 2: Children's Camp}

Fill the table to allocate the 46 children and eight adults to dormitories, keeping to all the rules.

\begin{tabular}{|l|l|l|l|}
\hline Dormitory & Number of Boys & Number of Girls & Name(s) of Adult(s) \\
\hline Red & & & \\
\hline Blue & & & \\
\hline Green & & & \\
\hline Purple & & & \\
\hline Orange & & & \\
\hline Yellow & & & \\
\hline White & & & \\
\hline
\end{tabular}




\section{Troubleshooting Task: Irrigation}

Below is a diagram of a system of irrigation channels for watering sections of crops. Gates A to $\mathrm{H}$ can be opened and closed to let the water go where it is needed. When a gate is closed, no water can pass through it.

This is a problem about finding a gate, which is stuck closed, preventing water from flowing through the system of channels.

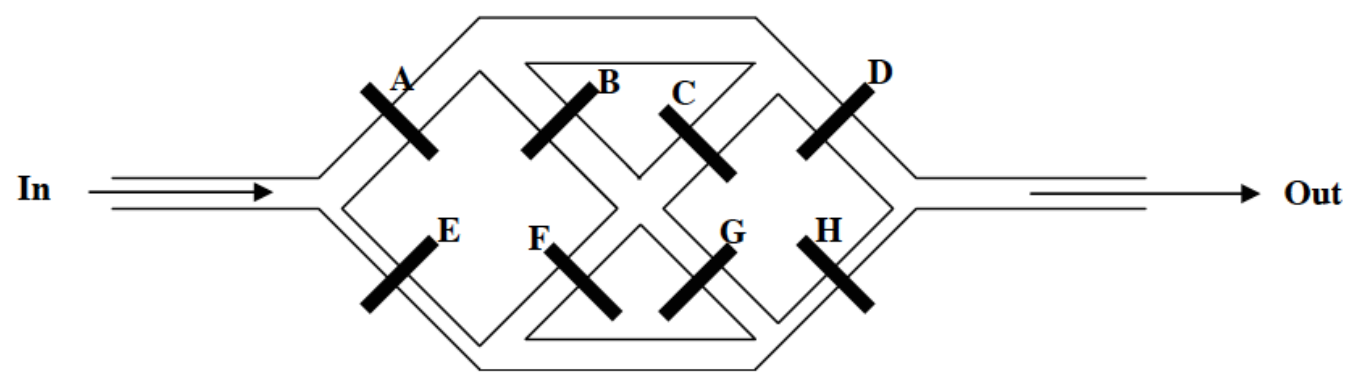

Michael notices that the water is not always going where it is supposed to. He thinks that one of the gates is stuck closed, so that when it is switched to open, it does not open.

\section{Question 3: Irrigation}

Michael used the following gate settings to test the gates.

\begin{tabular}{|c|c|c|c|c|c|c|c|}
\hline $\mathbf{A}$ & $\mathbf{B}$ & $\mathbf{C}$ & $\mathbf{D}$ & $\mathbf{E}$ & $\mathbf{F}$ & $\mathbf{G}$ & $\mathbf{H}$ \\
\hline Open & Closed & Open & Open & Closed & Open & Closed & Open \\
\hline
\end{tabular}

Michael finds that when the gates have the Table 1 settings, no water flows through, indicating that at least one of the gates set to "open" is stuck closed.

Decide for each problem case below whether the water will flow through all the way. Circle "Yes" or "No" in each case, and justify your response.

\begin{tabular}{|l|c|} 
Problem Case & $\begin{array}{c}\text { Will Water Flow } \\
\text { Through All the } \\
\text { Way? }\end{array}$ \\
\hline Gate A is stuck closed. All other gates are working properly as set in Table 1. & Yes/No \\
\hline Gate D is stuck closed. All other gates are working properly as set in Table 1. & Yes/No \\
\hline Gate F is stuck closed. All other gates are working properly as set in Table 1. & Yes/No \\
\hline
\end{tabular}




\section{Appendix B}

\section{The Modeling Self-Efficacy Scale}

The following scale measured students' self-efficacy beliefs related to each modeling problem. Students read the problem and respond to following questions on a scale ranging from 0 to 100 .

1. How sure are you that you can understand this mathematical problem?

$\begin{array}{lllllcccccc}0 & 10 & 20 & 30 & 40 & 50 & 60 & 70 & 80 & 90 & 100 \\ \text { Not at all sure } & & & & \text { Moderately sure } & & & & \text { Very sure }\end{array}$

2. How sure are you that you can determine a strategy to solve this problem?

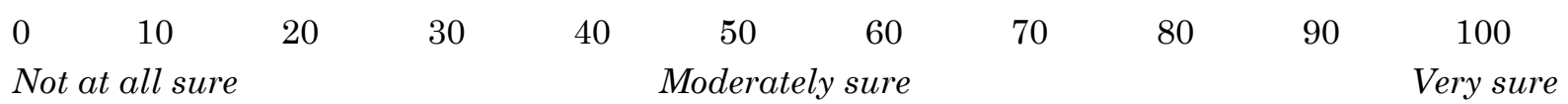

3. How sure are you that you can determine the information required to solve this problem?

$\begin{array}{lllllcccccc}0 & 10 & 20 & 30 & 40 & 50 & 60 & 70 & 80 & 90 & 100 \\ \text { Not at all sure } & & & & \text { Moderately sure }\end{array}$

4. How sure are you that you can solve this mathematical problem correctly?

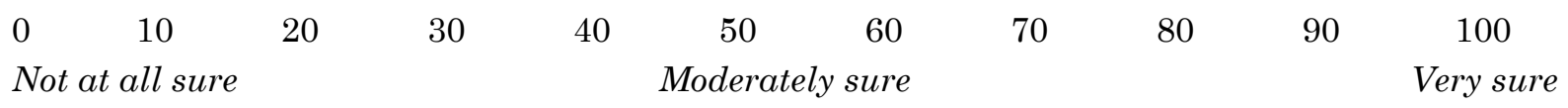




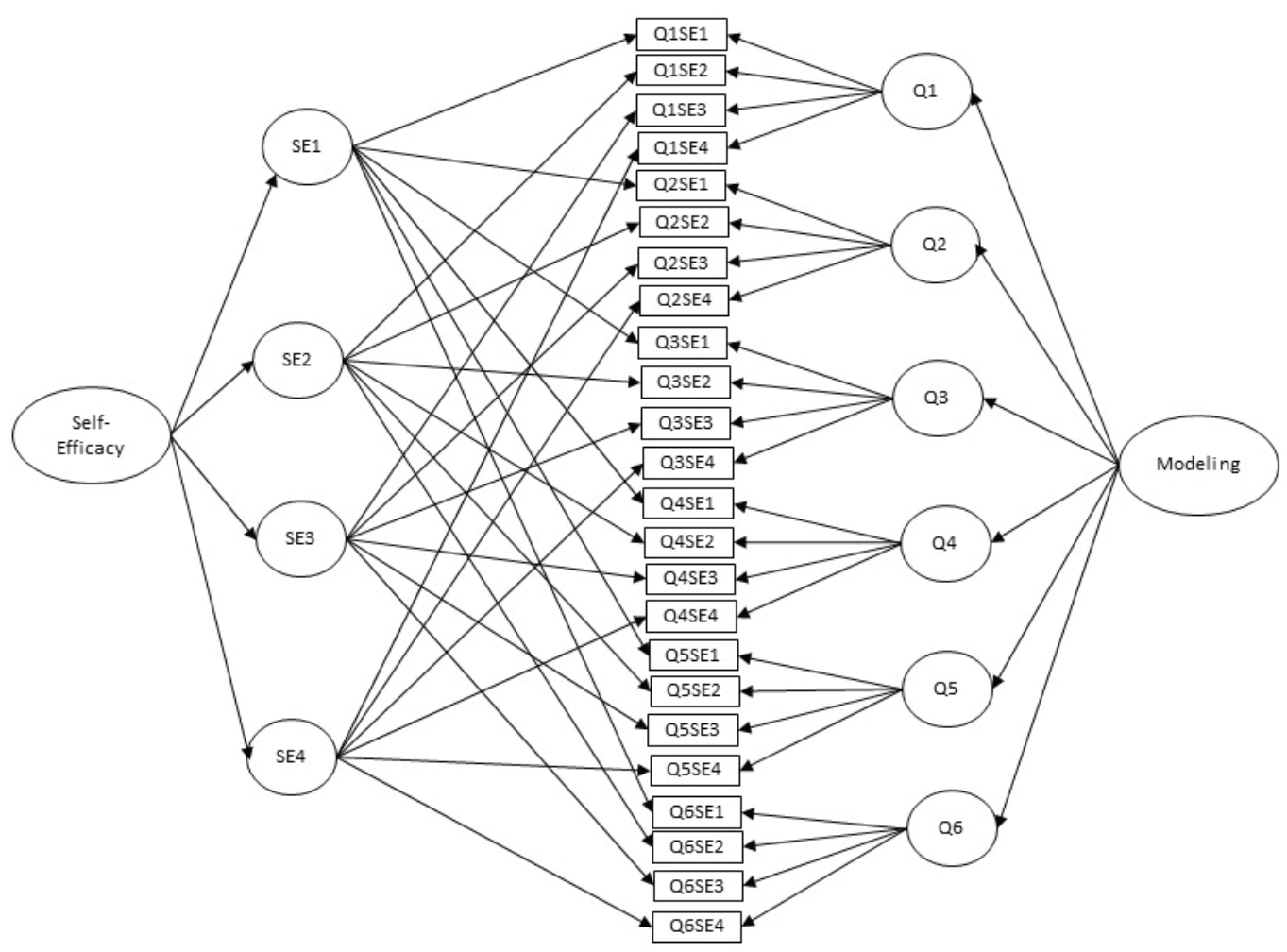

Figure B1. Confirmatory Factor Analysis Model. Self-Efficacy = overall higher order self-efficacy; SE1 = self-efficacy for understanding a problem; SE2 = self-efficacy for determining a strategy to solve a problem; SE3 = self-efficacy for determining information to solve a problem; SE4 = self-efficacy for solving a problem; Q1, Q2, Q3, Q4, Q5, and Q6 are the six modeling problems; Modeling = higher order overall modeling construct; Q1SE1, Q2SE1, Q3SE1, Q4SE1, Q5SE1, and Q6SE1 are participants' self-efficacy scores for understanding modeling problems Q1, Q2, Q3, Q4, Q5, and Q6, respectively; Q1SE2, Q2SE2, Q3SE2, Q4SE2, Q5SE2, and Q6SE2 are participants' self-efficacy scores for determining information for modeling problems Q1, Q2, Q3, Q4, Q5, and Q6, respectively; Q1SE3, Q2SE3, Q3SE3, Q4SE3, Q5SE3, and Q6SE3 are participants' self-efficacy scores for determining information for modeling problems Q1, Q2, Q3, Q4, Q5, and Q6, respectively; Q1SE4, Q2SE4, Q3SE4, Q4SE4, Q5SE4, and Q6SE4 are participants' selfefficacy scores for solving modeling problems Q1, Q2, Q3, Q4, Q5, and Q6, respectively. 
The Journal of Educational Research and Practice provides a forum for studies and dialogue that allows readers to better develop social change in the field of education and learning. Journal content may focus on educational issues of all ages and in all settings. It also presents peer-reviewed commentaries, book reviews, interviews of prominent individuals, and additional content. The objectives: We publish research and related content that examines current relevant educational issues and processes aimed at presenting readers with knowledge and showing how that knowledge can be used to impact social change in educational or learning environments. Additional content provides an opportunity for scholarly and professional dialogue regarding that content's usefulness in expanding the body of scholarly knowledge and increasing readers' effectiveness as educators. The journal also focuses on facilitating the activities of both researcher-practitioners and practitioner-researchers, providing optimal opportunities for interdisciplinary and collaborative thought through blogging and other communications.

Walden University Publishing: http://www.publishing.waldenu.edu 